\title{
TiN and $\mathrm{In}_{2} \mathrm{O}_{3} \mathrm{Co}$-sputtered Amorphous InTiON Electrodes for Perovskite Solar Cells
}

\author{
Ji-Eun Lee ${ }^{\mathrm{a}}$, Se-Phin Cho ${ }^{\mathrm{b}}$, Seok-Soon Kim ${ }^{\mathrm{b}, *}$, and Han-Ki Kim ${ }^{\mathrm{a}, *}$ \\ a School of Advanced Materials Science and Engineering, Sungkyunkwan University, \\ Gyeonggi-do 16419, Republic of Korea \\ ${ }^{b}$ Department of Nano and Chemical Engineering, Kunsan National University, Jeollabuk-do 753, Republic of Korea
}

Received November 9, 2018; revised November 16, 2018; accepted November 192018

\begin{abstract}
We report on transparent conducting TiN co-sputtered $\operatorname{In}_{2} \mathrm{O}_{3}$ electrodes prepared by multi-cathode magnetron sputtering at room temperature for use as transparent anodes in perovskite solar cells (PSCs). The completely amorphous structure with low resistivity of $1.29 \times 10-3 \Omega$-cm, work function of $4.69 \mathrm{eV}$, and high optical transmittance of $83.78 \%$ was produced by addition of Ti and $\mathrm{N}$ structural stabilizers in the $\operatorname{In}_{2} \mathrm{O}_{3}$ matrix, making amorphous InTiON (a-ITON) films suitable for use as transparent anodes in PSCs. In addition, the a-ITON films exhibited good mechanical flexibility under substrate bending due to their stable amorphous structure. Compared to amorphous ITO-based PSC, which exhibited a power conversion efficiency (PCE) of $12.07 \%$, the PSC with a-ITON showed a higher PCE of $13.74 \%$ due to higher optical transmittance inducing a higher photocurrent. The suitability of an a-ITON electrode suggests it as a potential candidate to substitute for conventional oxide electrodes.
\end{abstract}

Keywords: TiN, Flexible, Transparent conductive electrodes, Amorphous, Perovskite solar cells

\section{Introduction}

Perovskite solar cells (PSCs) have attracted noteworthy attention as promising low cost and highly efficient photovoltaics, following organic solar cells [1-4]. Because PSCs have a simple device structure (anode/perovskite active/cathode) and are easily fabricated using conventional printing processes, massive research in the academy and industry over the last 15 years has led to a high power conversion efficiency (PCE) of above $20 \%$, which is comparable to conventional Si-based photovoltaics [5-10]. In particular, organic-inorganic hybrid perovskites and planar structured PSCs provide high performance flexible thin film PSCs that can replace current inorganic photovoltaics such as $\mathrm{Si}, \mathrm{CdTe}$, and CuInGaSe [11-14]. However, the intensive research on increasing the PCE of PSCs has mostly focused on perovskite active layer, interfacial buffer layer, and passivation layer. Transparent anodes have not received similar attention due to a lack of transparent conducting oxide (TCO) materials. Although physically sputtered $\mathrm{Sn}_{-} \mathrm{In}_{2} \mathrm{O}_{3}$ (ITO) or chemically deposited $\mathrm{F}-\mathrm{SnO}_{2}$ (FTO) films have been employed as transparent anodes in most PSCs, development of high-

*Corresponding author

E-mail: hankikim@skku.edu, sskim@kunsan.ac.kr quality transparent anode materials to replace ITO and FTO is necessary. Because the short circuit current $\left(\mathrm{J}_{\mathrm{sc}}\right)$ and fill factor (FF) of PSCs are significantly affected by the optical and electrical properties of a transparent anode, design of high-quality transparent anode material is very important for obtaining high-performance PSCs with optimized PCE. In addition, amorphous transparent anodes prepared at room temperature are desirable for fabrication of PSCs because the wet etching process in electrode patterning is easier in amorphous than in crystalline electrode material. Although several anode materials such as conducting polymers, carbon-based electrodes, and nano-structured metals or mesh electrodes have been reported as transparent anodes in PSCs [15-17], conventional sputtering process-based oxide or oxynitride electrodes are more desirable considering the large coating area and mature sputtering process already established in industry. Several amorphous TCO electrodes such as $\mathrm{InZnO}, \mathrm{InSiO}$, InZnSnO, and InAlZnO have been reported by our group [18-21], but until now detailed investigation of cosputtered amorphous oxynitride films for use as transparent anodes has still been lacking. Oxynitride electrodes have several merits as transparent electrode material such as easy formation of amorphous structure, easy wet etching process, and existence of diverse oxynitride electrode materials. Therefore, development of an oxynitride electrodes 
prepared by co-sputtering would facilitate the further development of transparent anode materials.

In this work, we have investigated the electrical and optical of a TiN co-sputtered $\operatorname{In}_{2} \mathrm{O}_{3}$ (ITON) electrode on a glass substrate as a function of the RF and DC power ratio applied on TiN and $\operatorname{In}_{2} \mathrm{O}_{3}$ targets. With its use in mind as a transparent anode in PSCs, we optimized the electrical and optical properties of the amorphous ITON film. In addition, we demonstrated the effect of TiN co-sputtering on the amorphous structure of ITON films and the mechanical properties of ITON deposited on flexible PET substrate. Furthermore, we compared performance of PSCs based-on optimized ITON and reference ITO electrodes to show possibility of amorphous ITON as electrode material.

\section{Experimental details}

Amorphous ITON electrodes were deposited on glass substrate by methods of a dual target RF and DC magnetron sputtering system in a pure Ar environment at room temperature. Both TiN (Dasom RMS) and $\operatorname{In}_{2} \mathrm{O}_{3}$ (Dasom RMS) targets were located $100 \mathrm{~mm}$ from the substrate center, as shown in Fig. 1(a). For uniform cosputtering of TiN and $\mathrm{In}_{2} \mathrm{O}_{3}$ targets, we employed a tilted magnetron gun. To obtain optimal ITON electrodes, the ITON films were prepared on a glass substrate with dimensions of $25 \times 25 \mathrm{~mm}^{2}$ Fig. 1(b) as a function of DC power applied to $\operatorname{In}_{2} \mathrm{O}_{3}$ at a constant RF power of the TiN target $(10 \mathrm{~W})$. By adjusting the DC power of the $\mathrm{In}_{2} \mathrm{O}_{3}$ target, we could easily control the composition of the ITON electrode. In addition, the Ar flow rate and working pressure were maintained constant at $20 \mathrm{sccm}$ and $4 \mathrm{mTorr}$, respectively. For simplicity, the ITON electrode cosputtered at $\mathrm{In}_{2} \mathrm{O}_{3}$ DC power of $40 \mathrm{~W}$ is referred to as ' 40 W ITON' and so on. The deposition rate of the ITON electrode was obtained by means of a stylus profilometer (Tencor Alpha-step 250). The electrical properties of the ITON films such as sheet resistance, resistivity, mobility and carrier concentration were measured by a Hall measurement with van der Pauw geometry at room temperature. The optical transmittance of the ITON films was measured in the wavelength range of 400 to $800 \mathrm{~nm}$ by a UV/Visible spectrometer. The structure of the optimized ITON films were investigated by X-ray $\theta-2 \theta$ diffraction (XRD) measurements. The surface morphology and work function of ITON electrode was analyzed by a field emission scanning electron microscope (FESEM) and Kelvin probe force microscopy (KPFM), respectively. KPFM measurements were conducted using an atomic force microscopy (AFM) system (XE-100, Park Systems) under ambient conditions (temperature: $25.5^{\circ} \mathrm{C}$, humidity: $26 \%$ ). Conductive Pt-coated Si cantilevers (NSG 10/Pt, NT-MDT) were used for both work functions. To demonstrate the flexibility of amorphous ITON, we prepared the ITON on PET substrate. The mechanical properties of the ITON/PET sample were compared with a reference ITO/PET sample using a lab-designed inner and outer bending system as a function of bending radius. The outer bending test induced tensile stress on the film, whereas the inner bending test induced compressive stress. To investigate the feasibility of amorphous ITON electrode for PSCs, we fabricated planar type $\mathrm{MAPbI}_{3}$ based PSCs on the ITON/glass and ITO/glass. After cleaning ITON and ITO electrodes, substrates were treated with $\mathrm{UV} / \mathrm{O}_{3}$ plasma for $20 \mathrm{~min}$ to make the surface hydrophilic. Then, typical PEDOT:PSS (VPAI 4083) HTL was spin-coated by a two-step method (at $500 \mathrm{rpm}$ for $5 \mathrm{~s}$ and $5000 \mathrm{rpm}$ for 40 s) and annealed at $120{ }^{\circ} \mathrm{C}$ for $10 \mathrm{~min}$ in atmospheric conditions. $\mathrm{CH}_{3} \mathrm{NH}_{3} \mathrm{PbI}_{3}$ was spin-coated at $500 \mathrm{rpm}$ for 5 $\mathrm{s}$ and $5000 \mathrm{rpm}$ for $45 \mathrm{~s}$ using $45 \mathrm{wt} \%$ solution of $\mathrm{CH}_{3} \mathrm{NH}_{3} \mathrm{I}$ and $\mathrm{PbI}_{2}$ with a 1:1 molar ratio. During the second step of the spin-coating process, $0.7 \mathrm{ml}$ toluene was dropped to obtain high quality perovskite films and subsequent thermal annealing was performed at $100{ }^{\circ} \mathrm{C}$ for $10 \mathrm{~min}$. The PCBM solution (20 mg PCBM in $1 \mathrm{ml}$ chlorobenzene) was spin-coated at $1000 \mathrm{rpm}$ for $60 \mathrm{~s}$ on perovskite films and $\mathrm{BCP} / \mathrm{Ag}$ was thermally evaporated on the PCBM layer as the top metal electrode. The photocurrent density-voltage $(\mathrm{J}-\mathrm{V})$ curves were obtained using a Keithley 2400 under standard condition illumination $\left(100 \mathrm{~mW} / \mathrm{cm}^{2}\right.$ with AM $1.5 \mathrm{G}$ conditions after calibration of light intensity with a certified reference Si solar cell).

\section{Results and discussion}

Figure 2(a) shows the ITON electrode Hall measurement results as a function of the DC power applied to the $\operatorname{In}_{2} \mathrm{O}_{3}$ target from 40 to $100 \mathrm{~W}$ at a constant RF power of TiN (10
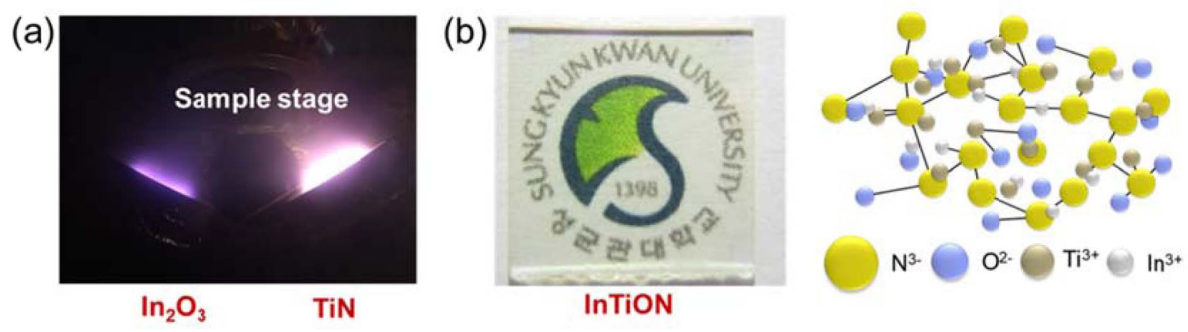

Figure 1. (a) Picture of plasma on $\mathrm{In}_{2} \mathrm{O}_{3}$ and TiN targets during the co-sputtering process of growing amorphous ITON electrodes. (b) Picture of ITON/glass sample and schematic atomic structure of amorphous ITON electrode. 

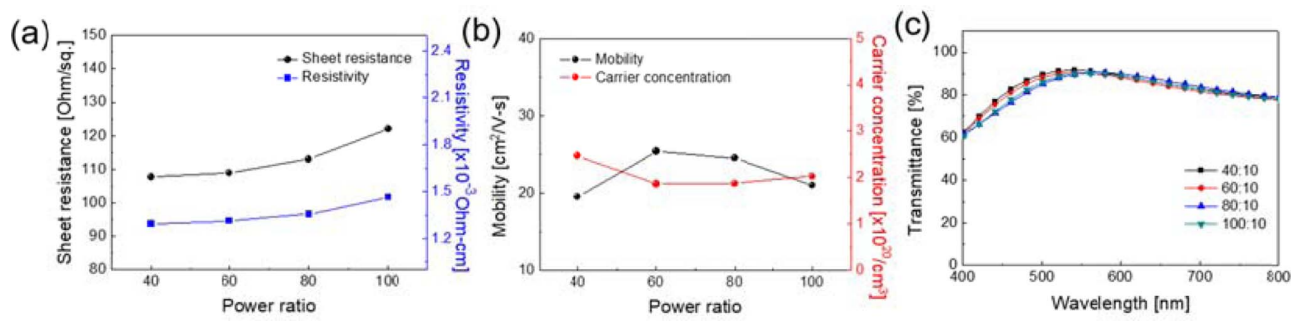

Figure 2. Hall measurement results of co-sputtered ITON films as a function of $\operatorname{In}_{2} \mathrm{O}_{3}$ DC power: (a) sheet resistance, resistivity, (b) carrier mobility and concentrations. (c) Optical transmittance of the ITON films with increasing $\operatorname{In}_{2} \mathrm{O}_{3}$ DC power.

Table I. Electronical properties of ITON and ITO films.

\begin{tabular}{ccccc}
\hline \hline Electrode & $\begin{array}{c}\text { Sheet } \\
\text { resistance } \\
{[\text { Ohm } / \mathrm{sq} .]}\end{array}$ & $\begin{array}{c}\text { Resistivity } \\
{\left[\times 10^{-3}\right.} \\
\text { ohm-cm }]\end{array}$ & $\begin{array}{c}\text { Mobility } \\
{\left[\mathrm{cm}^{2} / \mathrm{V}-\mathrm{s}\right]}\end{array}$ & $\begin{array}{c}\text { Carrier } \\
\text { Concentration } \\
{\left[/ \mathrm{cm}^{3}\right]}\end{array}$ \\
\hline ITON & 107.8 & 1.29 & 19.5 & $2.47 \times 10^{20}$ \\
ITO & 38.27 & 0.45 & 34.8 & $3.90 \times 10^{20}$ \\
\hline
\end{tabular}

Table II. Optical properties of ITON and ITO films.

\begin{tabular}{ccc}
\hline \hline Electrode & $\begin{array}{c}\text { Transmittance Average [\%] } \\
(400 \sim 800 \mathrm{~nm})\end{array}$ & $\begin{array}{c}\text { Transmittance [\%] } \\
(500 \mathrm{~nm})\end{array}$ \\
\hline ITON & 83.78 & 91.46 \\
ITO & 82.98 & 90.73 \\
\hline
\end{tabular}

W). As shown in Fig. 2(a), the sheet resistance and resistivity of 100-nm-thick ITON films slightly increased with increasing DC power of $\operatorname{In}_{2} \mathrm{O}_{3}$. At an $\mathrm{In}_{2} \mathrm{O}_{3}$ DC power level of $40 \mathrm{~W}$ and TiN RF power of $10 \mathrm{~W}$, the $40 \mathrm{~W}$ ITON films showed the lowest resistivity of $1.29 \times 10^{-3} \Omega$-cm and the lowest sheet resistance of $107.8 \Omega /$ square. The lowest resistivity of $40 \mathrm{~W}$ ITON film can be attributed to the highest carrier concentration of $2.47 \times 10^{20} \mathrm{~cm}^{-3}$ compared to other ITON films. As shown in Fig. 1(b), the effective doping of $\mathrm{Ti}^{4+}$ ions in the ITON electrode led to high carrier concentration in the ITON film. In addition, oxygen vacancies in the $\operatorname{In}_{2} \mathrm{O}_{3}$ matrix provided excess electrons $[22,23]$. However, further increase in $\operatorname{In}_{2} \mathrm{O}_{3} \mathrm{DC}$ power led to slightly increased sheet resistance and resistivity due to decreased carrier concentration. Figure 2(c) shows the optical transmittance of ITON films as a function of $\mathrm{In}_{2} \mathrm{O}_{3}$ DC power. Irrespective of the DC power used to fabricate the ITON films, all ITON films showed similar optical transmittance in the visible wavelength region, with typical spectral shape of an amorphous structure. Especially, the optical transmittance in the 400$550 \mathrm{~nm}$ region slightly decreased with increased $\operatorname{In}_{2} \mathrm{O}_{3}$ DC power. The 40W ITON film showed the highest optical transmittance of $91.46 \%$ at $550 \mathrm{~nm}$. Based on Figs. 2(a) and 2(c), we found that the 40W ITON film had the highest figure of merit $\left(\mathrm{T}^{10} / \mathrm{R}_{\mathrm{sh}}\right)$ value of $1.58 \times 10^{-3} / \mathrm{Ohm}[24]$. Table I and II compares electrical and optical properties of the TION and reference ITO electrodes.

Figure 3(a) shows the XRD plot of the 40W ITON films grown on a glass substrate. There are no crystalline peaks related to bixbyite structure of $\operatorname{In}_{2} \mathrm{O}_{3}$. The broad halo pattern designates the completely amorphous structure of the $40 \mathrm{~W}$ ITON film. The ITON films cannot show the typical bixbyite structure of $\operatorname{In}_{2} \mathrm{O}_{3}$ due to the Ti and $\mathrm{N}$ dopants act as structure stabilizers in the $\operatorname{In}_{2} \mathrm{O}_{3}$ matrix as shown in Fig. 1(b) [25]. In a typical bright-field transmission electron microscope (TEM) image [inset of Fig. 3(a)], the uniform gray contrast of the ITON film shows that the cosputtered ITON film was completely amorphous, consistent with the XRD plot. Figure 3(b) compares the work functions of the ITO and 40W ITON films. As illustrated

(a)

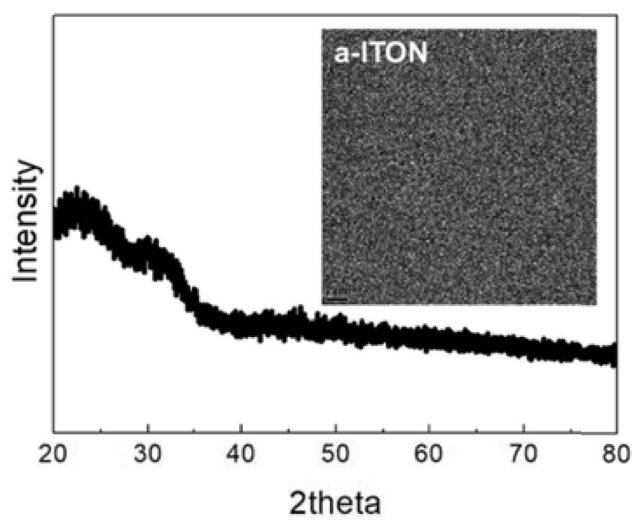

(b)

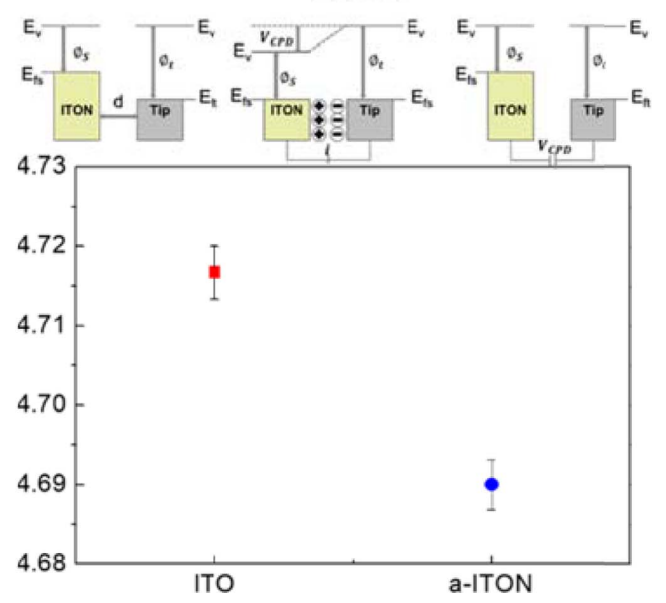

Figure 3. (a) XRD plot of 40W ITON film on a glass substrate. The inset shows the HREM image of the 40W ITON film. (b) Work functions of reference ITO and co-sputtered ITON films measured by Kelvin probe force microscopy (KPFM). Upper panels illustrate the principle of work function measurement by KPFM. By measuring the contact potential difference (CPD) against the tip, the work function of the ITON was measured. 
(a)

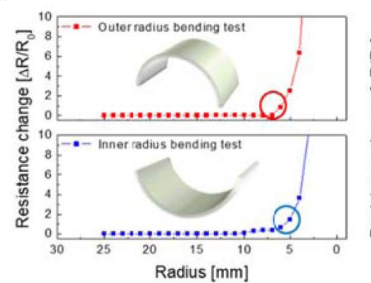

(c)

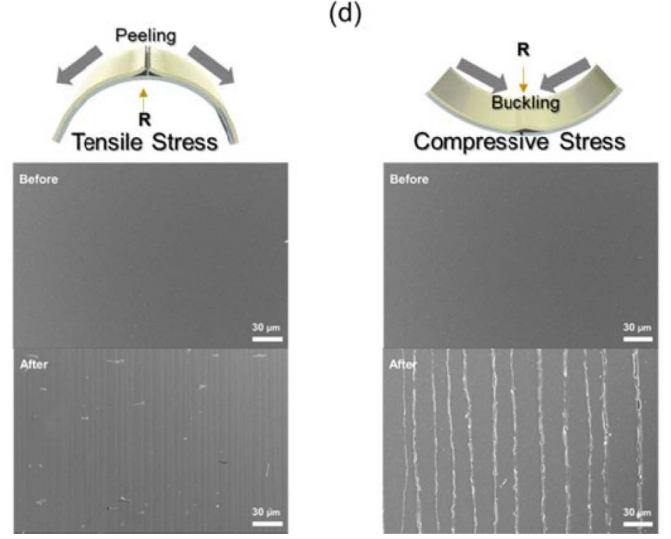

Figure 4. (a) Outer bending and inner bending test results for the ITON/PET with decreasing bending radii. Dynamic outer and inner bending test results for the ITON/PET for 10,000 cycles. FESEM images of the ITON film before and after bending test beyond critical bending radius of 7 and $6 \mathrm{~mm}$; (c) outer bending and (d) inner bending results.

in the upper panels of Fig. 3(b), we obtained surface work functions of the ITON film at different surface regions using a KPFM system. The standard error of the work function data was very small (less than $0.31 \%$ ), which suggests that the ITON alloy thin film had a homogeneous composition. Compared to the work function of ITO electrode, the 40W ITON film had a lower work function of $4.69 \mathrm{eV}$ due to the existence of the TiN component with its work function of $4.25 \mathrm{eV}$ [26].

Although we didn't fabricate flexible PSCs in this work, we did investigate the flexibility of amorphous ITON grown on PET substrate to show the potential of the ITON as a flexible and transparent electrode suitable for flexible PSCs. At identical sputtering conditions, the $40 \mathrm{~W}$ ITON film was sputtered on the PET substrate at room temperature. Figure 4(a) shows the outer/inner bending tests of the ITON/PET sample as a function of outer/inner bending radii. The resulting change in the resistance of the ITON film can be expressed as $\left(\mathrm{R}-\mathrm{R}_{0}\right) / \mathrm{R}_{0}$, where $\mathrm{R}_{0}$ mean the initial measured resistance and $\mathrm{R}$ is the resistance measured under substrate bending. The results of the outer bending in Fig. 4(a) show that the ITON film had constant resistance until the bending radius reached $7 \mathrm{~mm}$. Based on the following equation, we can calculate the peak strain for the curved ITON film with decreasing bending radius [27]. (a)

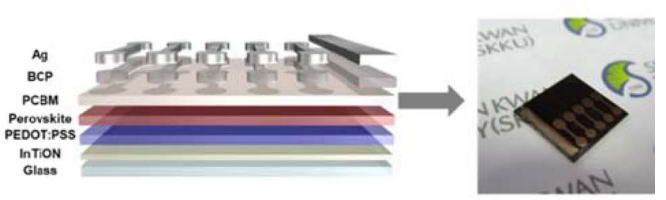

(b)

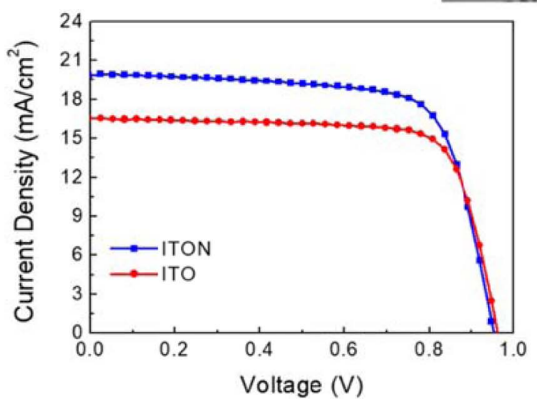

(c)

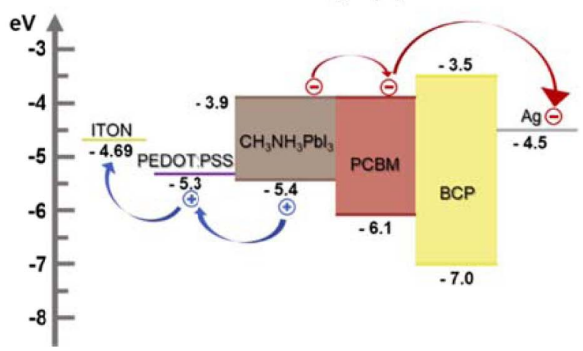

Figure 5. (a) Schematic device structure fabricated on cosputtered ITON electrode and picture of PSC with ITON electrode. (b) Representative J-V curves of PSC fabricated on ITO and ITON electrodes. (c) Energy band diagram of each layer in PSCs fabricated on ITON electrode.

Table III. Comparison of the performances of hybrid solar cells fabricated on reference ITO and ITON electrodes with an additional perovskite active layer.

\begin{tabular}{ccccc}
\hline \hline Electrode & $\begin{array}{c}\mathrm{J}_{\mathrm{sc}} \\
{\left[\mathrm{mA} / \mathrm{cm}^{2}\right]}\end{array}$ & $\begin{array}{c}\mathrm{V}_{\text {oc }} \\
{[\mathrm{V}]}\end{array}$ & $\begin{array}{c}\mathrm{FF} \\
{[\%]}\end{array}$ & $\begin{array}{c}\text { PCE } \\
{[\%]}\end{array}$ \\
\hline ITON & 20.08 & 0.95 & 71.76 & 13.74 \\
ITO & 16.53 & 0.96 & 75.91 & 12.07 \\
\hline
\end{tabular}

$$
\operatorname{Strain}(\varepsilon)=\frac{d_{I T O N}+d_{P E T}}{2 R} \times 100
$$

Here, $d_{\text {ITON }}$ and $d_{\text {PET }}$ are the thicknesses of the amorphous ITON and the PET substrate, respectively. Bending a 120 -nm-thick ITON film on a 125 - $\mu$ m-thick PET substrate to a bending radius of $6 \mathrm{~mm}$ resulted in the resistance dramatically increased and reached a strain of $0.83 \%$. Further decreasing the outer bending radius caused more rapid increases in the resistance due to crack formation and propagation, as shown in Fig. 4(c). In the inner bending tests, the measured resistance of the ITON film was constant until the sample was bent to an inner bending radius of $6 \mathrm{~mm}$. At the $5 \mathrm{~mm}$ bending radius, the ITON film experienced its peak strain value of $1.49 \%$. To investigate mechanical stability under repeated bending, dynamic outer/inner bending cycling tests were also performed, as shown in Fig. 4(b). Both the outer and inner dynamic bending fatigue tests showed no change in resistance after 10,000 cycles because of the superior 
flexibility of the amorphous ITON films. Figures 4(c) and 4(d) showed the FESEM images of the ITON films before and after inner and outer bending. Depending on bending mode, the ITON film showed different crack shapes. Compared to outer bending, the inner bending sample showed greater distance between cracks. As illustrated in Fig. 4(b), the outer bending sample showed peeling caused by tensile stress. On the other hand, the inner bending sample showed buckling due to compressive stress.

To confirm the feasibility of co-sputtered ITON film as a transparent anode for PSC, we fabricated planar heterojunction PSC consisting of TCO (ITON and ITO)/ PEDOT:PSS HTL/ $\mathrm{CH}_{3} \mathrm{NH}_{3} \mathrm{PbI}_{3} / \mathrm{PCBM} / \mathrm{BCP} / \mathrm{Ag}$ [See Fig. 5(a)]. Figure 5(b) shows the representative J-V curves of PSCs fabricated on ITON and ITO, and important parameters are summarized in Table III. Compared to ITO based PSC with a PCE of $12.07 \%$, the ITON based PSC exhibited higher PCE of $13.74 \%$. In particular, $\mathrm{J}_{\mathrm{sc}}$ was dramatically improved by replacing typical ITO with ITON. Higher $\mathrm{J}_{\mathrm{sc}}$ might be attributed to the higher optical transmittance of ITON compared to ITO electrode. However, due to the existence of PEDOT:PSS HTL as illustrated in the energy diagram [Fig. 5(c)], both PSCs showed similar open circuit voltages $\left(\mathrm{V}_{\mathrm{oc}}\right)$ of 0.95 (ITON) and 0.96 (ITO) V. This indicates that PEDOT:PSS in our PSCs induces sufficient extraction of holes from the perovskite active layer regardless of the work function of the anodes. Further optimization and study of the relationship between optical and electrical properties with overall photovoltaic performance are currently underway.

\section{Conclusions}

We have demonstrated the feasibility of TiN and $\operatorname{In}_{2} \mathrm{O}_{3}$ co-sputtered ITO electrodes used as another type of anode material in PSCs. The addition of Ti and $\mathrm{N}$ structural stabilizers in the $\mathrm{In}_{2} \mathrm{O}_{3}$ matrix produced a completely amorphous structure with a sheet resistance of 107.8 $\mathrm{Ohm} / \mathrm{square}$, optical transmittance of $83.78 \%$, and work function of $4.69 \mathrm{eV}$, making amorphous InTiON (a-ITON) films suitable for use as transparent anodes for PSCs. In addition, the a-ITON films exhibited good mechanical flexibility under substrate bending due to their stable amorphous structure. Relative to the power conversion efficiency $(12.07 \%)$ of the amorphous ITO-based PSCs, PSC with a-ITON showed a superior power conversion efficiency of $13.74 \%$ due to its high optical transmittance. This indicates the potential of the amorphous oxynitride electrode to contribute to high performance PSCs.

\section{Acknowledgements}

This work was supported by a National Research Foundation of Korea (NRF) grant funded by the Korean government (MSIP) (No. 2018R1A2B2003826), the Korea Institute of Energy Technology Evaluation and Planning (KETEP) and the Ministry of Trade, Industry \& Energy (MOTIE) of the Republic of Korea (No. 2016301 0012200).

\section{References}

[1] H. J. Snaith, J. Phys. Chem. Lett. 4, 3623 (2013).

[2] N. Jeon, J. Noh, W. Yang, Y. Kim, S. Ryu, J. Seo, and S. Seok, Nature 517, 476 (2015).

[3] W. Nie, H. Tsai, R. Asadpour, J. C. Blancon, A. J. Neukirch, G, Gupta, J. J. Crochet, M. Chhowalla, S. Tretiak, M. A. Alam, H. L. Wang, and A. D. Mohite, Science 347, 522 (2015).

[4] F. Zhang, X. Yang, M. Cheng, W. Wang, and L. Sun, Nano Energy 20, 108 (2016).

[5] S. Shin, W. Yang, J. Noh, J. Suk, N. Jeon, J. Park, J. Kim, W. Seong, and S. Seok, Nat. Commun. 6, 7410 (2015).

[6] H. C. Weerasinghe, Y. Dkhissi, A. D. Scully, R. A. Caruso, and Y. B. Cheng, Nano Energy 18, 118 (2015).

[7] J. Jo, M. S. Seo, M. Park, J. Y. Kim, J. Park, I. Han, H. Ahn, J. Jung, B. H. Sohn, M. Ko, and H. Son, Adv. Funct. Mater. 26, 4464 (2016).

[8] C. Roldán Carmona, O. Malinkiewicz, A. Soriano, G. Espallargas, A. Garcia, P. Reinecke, T. Kroyer, M. Dar, M. Nazeeruddin, and H. Bolink, Energy Environ. Sci. 7, 994 (2014).

[9] J. Heo, M. Lee, H. Han, B. Patil, J. Yu, and S. Im, J. Mater. Chem. A. 4, 1572 (2016).

[10] D. Yang, R. Yang, Z. Zhang, Z. Yang, S. Liu, and C. Li, Energy Environ. Sci. 8, 3208 (2015).

[11] M. Liu, M. Johnston, and H. Snaith, Nature 501, 395 (2013).

[12] D. Liu and T. Kelly, Nat. Photonics 8, 133 (2014).

[13] J. Y. Jenh, Y. F. Chiang, M. H. Lee, S. R. Peng, T. F. Guo, P. Chen, and T. C Wen, Adv. Mater. 25, 3727 (2013).

[14] Q. Jiang, L. Zhang, H. Wang, X. Yang, J. Meng, H. Liu, Z. Yin, J. Wu, X. Zhang, and J. You, Nat. Energy 2, 16177 (2016).

[15] H. Sung, N. Ahn, M. Jang, J. K. Lee, H. Yoon, N. G. Park, and M. Choi, Adv. Energy Mater. 6, 1501873 (2016).

[16] J. Heo, D. Shin, S. Kim, M. Jang, M. Lee S. Seo, S. H. Choi, and S. Im, Chem. Eng. J. 323, 153 (2017).

[17] Y. Jin, Y. Sun, K. Wang, Y. Chen, Z. Liang, Y. Xu, and F. Xiao, Nano Res. 11, 1998 (2018).

[18] J. Kim, S. I. Na, and H. K. Kim, Sol. Energy Mater. Sol. Cells 98, 424 (2012).

[19] H. J. Kim, K. W. Seo, Y. J. Noh, A. Sohn, D. W. Kim, and H. K. Kim, Sol. Energy Mater. Sol. Cells 141, 194 (2015).

[20] H. M. Lee, S. B. Kang, K. B. Chung, and H. K. Kim, Appl. Phys. Lett. 102, 021914 (2013).

[21] J. H. Bae and H. K. Kim, Thin Solid Films 516, 7866 (2008).

[22] P. Wu, Q. Li, X. Zou, W. Cheng, D. Zhang, C. Zhao, L. Chi, and T. Xiao, J. Phys.: Conf. Ser. 188, 012054 (2009).

[23] O. Bierwagen and J. S. Speck, Appl. Phys. Lett. 101, 102107 (2012).

[24] G. Haacke, J. Appl. Phys. 47, 4086 (1976).

[25] D. Y. Cho, K. H. Kim, T. W. Kim, K. B. Jeong, and H. K. Kim, Organic Electronics 24, 227 (2015).

[26] M. Ebaid, J. W. Min, C. Zhao, T. Ng, H. Idriss, and B. Ooi, J. Mater. Chem 6, 6922 (2018).

[27] J. G. Kim, J. E. Lee, S. Jo, B. Chin, J. Y. Baek, K. J. Ahn, S. Kang, and H. K. Kim, Sci. Rep. 8, 12019 (2018). 